\title{
RUPTURE OF THE STOMACH,
}

\author{
AND \\ ESCAPE OF ITS CONTENTS,
}

IN'TO THE

\section{CAVITY OF THE ABDOMEN.}

BY JOHN CRAMPTON, M.D.

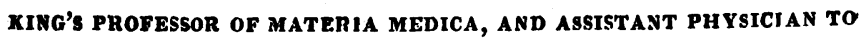
STEVEN'S HOSPITAL, DUBLIN.

COMMUNICATED BY

DR. BAILLIE.

wITH

\section{ADDITIONAL OBSERVATIONS}

By BENJAMIN TRAVERS, Esq. F.R.S. SURGEON TO SAINT THOMA8's HOSYITAX, AND VICE-PRESIDENT OF THE SOCIETY.

Read Nov. 12, 1816.

A.T three o'clock in the afternoon, October 19, 1816, Miss H. of a sallow complexion, spare habit, aged twenty-nine, was seized with a spasm, as she called it, in the stomach, which threatened immediate dissolution. She had been subject occasionally to pain in that viscus, as well as in both the hypochondria, but they generally gave way to medical treatment of a few days. 
- At five o'clock, when I saw her, she suffered agonizing pains in the whole abdomen; they seemed to originate from the scrobiculus cordis as a centre, and shot to the hypochondrium, to the back and even to the shoulders. The belly was hard, the abdominal muscles being strongly contracted, but not tumid; pulse not hurried; tongue clean; bowels slow for two days; had ate her breakfast as usual, and taken oatmeal porridge for luncheon; she had no nausea or disposition to vomit, but she was anxious to take an emetic, to which I did not consent.

At seven o'clock her pulse was 100; the skin hot; the pains were still more urgent.

At ten o'clock the pulse was 120 ; much smaller; breathing quick; shortly after this the capillary circulation seemed to fail.

At twelve o'clock the pulse could scarcely be felt; the hands, feet, and knees were cold; the face livid; the breathing more embarrassed. Although her dissolution was evidently approaching, there was not the least remission of pain. She moaned incessantly; her respiration became gradually shorter; her extremities colder; her stomach never rejecting either drink or medicine; retaining her senses and intellect perfect to the last. She gradually sunk, and expired in agony, at three o'clock in the morning. 
It is unnecessary to detail the medical treatment; suffice it to say, that bleeding, both general and local, fomentations, mild purgatives, glysters in the usual form, besides those administered from a large syringe, blisters and the warm bath, were all resorted to without delay, and pushed to their fullest extent; they made no impression on the disease, nor did an opiate, given when recovery seemed out of the question, afford any respite from pain.

An examination of the body was obtained the ensuing day, thirty-six hours after death, when the following appearances presented themselves.

On opening the abdomen, the stomach was observed to be pale, flaccid, and empty; its contents, amongst which were recognized oatmeal and castor oil, had escaped into the cavity of the abdomen, through a round aperture situated on its anterior surface, at the union of the cardiac and pyloric portions. This perforation of the stomach was perfectly circular, about the size of a pea, and appeared to be the result of an ulcer on the mucous surface, which had gradually penetrated the other coats. This ulcer was hollow and circular, nearly the size of a shilling, and had the appearance as if it had been made with caustic, with the orifice in its centre.

There were extensive and recent signs of inflammation throughout the whole peritoneum, investing 
the intestines, which appeared as if injected, and exsudations of lymph, which connected the convolutions of the intestines to each other by adhesion. The liver and spleen appeared shrunk and flaccid, not indurated; the gall-bladder contained some yellow bile; the urinary-bladder appeared empty and contracted.

\section{ADDITIONAL OBSERVATIONS}

B. BENJAMIN TRAVERS, EsQ. F.R.S. AND VICE-PRESIDENT OF THE SOCIETY.

The case of an aperture formed in consequence of an ulcer of the mucous coat, in the stomach and intestines, and giving issue to their contents, although not of very frequent occurrence, has been recorded by several anatomists. I have added a case strikingly similar to that related by Dr. Crampton, which occurred under my observation some years ago, and a communication or two from a friend, with a few remarks; not with an idea of affording a practical suggestion in a case which sets all art at defiance, but for the purpose of further illustrating the subject. 